\title{
$\mathrm{QR}$ 코드 기반 가상패션점포의 지각된 혜택과 위험요소에 대한 탐색적 연구
}

\section{An Exploratory Study of Perceived Benefits and Risks for QR Code based Virtual Fashion Stores}

\author{
김은영 · 이미영* \\ 충북대학교 패션디자인정보학과 ·인하대학교 의류디자인학과 \\ Kim, Eun Young $\cdot$ Lee, MiYoung* \\ Dept. of Fashion Design Information, Chungbuk National University \\ Dept. of Fashion Design \& Textiles, Inha University
}

\begin{abstract}
This study explores critical and success factor of benefits and risks for predicting the acceptance of QR code virtual fashion stores. As an exploratory approach, this study conducted focus group interviews(FGI) with 21 panels who had experience with selected QR virtual stores (e.g., Home plus, 11th Street, Pin \& Fit). Content analysis was used to generate 184 excerpts and classify into benefits and risks related to QR code virtual stores. With respect to benefits, content analysis identified four factors: Affective appeal, perceived usefulness, ubiquity, and brand promotion. Also, contents regarding perceived risks were classified into four factors: Complexity, lack of information, lack of technology infrastructure, and perceived cost. A managerial implication was discussed for predicting consumer technology acceptance of a QR code virtual store in the fashion retailing market.
\end{abstract}

Keywords: perceived benefit, risk, QR code, virtual fashion store, qualitative research

\section{I. 서 론}

디지털 기술 혁신에 따른 뉴 미디어의 등장은 과거 와 달리 소비자의 욕구뿐 아니라 커뮤니케이션과 네 트워크 형성 및 시장 환경까지 변화시키고 있다. 최근
에는 스마트 폰 사용자의 증가로 인해 모바일 시장이 더욱 빠르게 성장하고 있으며, 이러한 상황에서 다양 한 디지털 기술의 적용은 멀티채널전략의 새로운 패 러다임으로 제시되고 있다.

최근 스마트앱 기반 $\mathrm{QR}$ 코드를 활용한 가상점포는 제4

\footnotetext{
* Corresponding Author: Lee, MiYoung

Tel: +82-32-860-8137, Fax:+82-32-865-8130

E-mail: mylee@inha.ac.kr
} 
세대 유통모델로 제시되면서 앞으로 점점 진화될 것이라 고 예측하고 있다 (Choi, 2011a; Song, 2012). 2011년

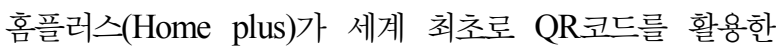
"스마트 가상 점포(Smart virtual store)"를 소개한 이후 (Kim, 2011; "Top 10", 2013), 식료품 및 생활용품, 의 류, 액세서리, 도서, 전자기기 등 다양한 산업영역으로 그 적용범위가 확대되고 있다. 실제로 홈플러스의 경우, $\mathrm{QR}$ 코드 가상점포를 진행하는 동안 온라인 매출은 $130 \%$ 정도 증가했다고 보고되었다(Shin, 2012; "Top 10," 2013). 이러한 QR코드 기반 스마트 가상점포는 오프라 인과 온라인의 장점을 결합한 멀티채널 전략의 수단으로 서 $(\mathrm{Gu}, 2011)$, 고객의 라이프스타일을 고려한 시간적, 공 간적 제약이 없는 쇼핑의 편리성과 유용성을 제공할 뿐 아니라 제품이나 서비스의 정보력을 갖는다는 점에서 성 장가능성은 매우 크다고 본다.

지금까지 $\mathrm{QR}$ 코드에 관한 연구의 대부분은 광고에 초 점을 두고 $\mathrm{QR}$ 코드기술 활용의 성공적 사례를 분석하였 다(Kwon \& Min, 2011;Lee et al., 2011; Shim \& Go, 2012). 예를 들면, Lee et al(2011)의 연구에서는 스마트 폰을 활용한 광고사례분석을 통해 $\mathrm{QR}$ 코드의 핵심기술 (증강현실, 위치기반, 모바일 커머스)융합에 의한 진화모 형을 제안하였다. 또한, 소비자 관점에서 Shim과 $\mathrm{Go}(2012)$ 는 디지털 사이니지와 모바일을 연계한 $\mathrm{QR} ㅋ ㅗ$ 드 광고맥락에서 소비자 이용 동기 변인으로 유행선도와 혜택추구가 $\mathrm{QR}$ 코드에 대한 태도에 정적효과를 보인다고 밝혀 QR코드의 수용의도를 예측하였다.

특히, 패션분야에서 $\mathrm{QR}$ 코드 기반 디지털 기술을 적용 할 경우 상황과 시간의 제약 없이 쇼핑의 편리성과 유용 성을 제공할 뿐 아니라(Grewal et al., 2011; Shim \& $\mathrm{Go}, 2012)$ 더욱 훙미로운 쇼핑체험을 향상시킬 수 있으 므로 패션제품과 같은 체험적 상품(experiential product) 에서의 $\mathrm{QR}$ 코드 활용가능성은 더욱 관심이 집중되고 있 다. 패션 마케팅 관점에서 볼 때, $\mathrm{QR}$ 코드의 기술에 의 한 실시간 정보를 제공할 수 있는 편재성(Ubiquity)은 적은 비용으로 많은 잠재고객을 확보할 수 있을 뿐 아니 라 광고 및 판촉과 같은 마케팅 커뮤니케이션 전략에 활 용가치가 높을 것으로 예상하고 있다(Jung, 2010; Lee \& Chung 2011; Lee \& Kim, 2011; Lee et al., 2011). 이와 같은 긍정적 시각에도 불구하고 아직까지 $\mathrm{QR}$ 코 드 기반 정보시스템에 대한 인식이 부족하여 소비자들에
게 빠르게 수용되지 않고 있으며, 이에 많은 기업들이 $\mathrm{QR}$ 코드기반 스마트 가상점포의 미래 발전 가능성에 대 한 확신을 하지 못하고 있는 실정이다(Yang, 2012). 더 욱이 타 산업에 비해 패션산업에서는 $\mathrm{QR}$ 코드 가상점포 를 일시적으로 오픈하고 있으나 실제로 성공사례는 매우 적다. 예를 들면, 핀앤핏, 11 번가, 웨스트우드, 멋남은 스 마트폰에 익숙하며 혁신적 기술을 상대적으로 쉽게 수용 하는 특정 젊은 고객층을 목표로 하고 있음에도 불구하 고 일시적으로 브랜드 홍보의 수단으로 사용할 뿐 가상 점포로서의 기능을 상실한 경우가 대부분이다(Han, 2012). 따라서 QR코드 기술을 활용한 가상패션점포의 지각된 혜택 또는 위험요소를 탐색함으로써 소비자의 수

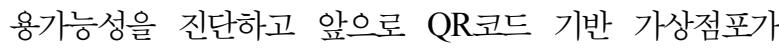
나아가야 할 방안을 모색해야 할 필요가 있다고 본다.

본 연구에서는 $\mathrm{QR}$ 코드 가상점포가 초기단계에 있으므 로 실증적 연구에 앞서 $\mathrm{QR}$ 코드 가상점포에 관한 문헌고 찰과 표적집단면접(Focus Group Interview: FGI)을 이용 한 질적연구를 수행하고자 한다. 구체적인 연구목적은 소비자 관점에서 $\mathrm{QR}$ 코드 가상점포에 대한 전반적인 인 식을 파악하고, $\mathrm{QR}$ 코드 패션가상점포의 지각된 혜택과 위험요소를 탐색하고자 한다. 본 연구는 점포맥락에서 $\mathrm{QR}$ 코드 기술의 활용가치를 평가하고 소비자의 수용가능 성을 진단함으로써 $\mathrm{QR}$ 코드 기반 가상패션점포맥락에서 기술수용모델을 확대할 수 있을 것이다. 또한, 가상점포 의 부가적 가치 창출을 위한 효과적인 비즈니스 솔루션 을 얻는데 기여할 수 있을 것이라 사료된다.

\section{II. 이론적 고찰}

\section{1. 신기술로서의 $Q R$ 코드}

최근 디지털 기술의 새로운 혁신으로서 "QR코드" (Quick Response Codes) 기술의 적용이 확대되고 있다. 1994년 일본의 덴소사에 의해 개발된 QR코드는 기존 1 차원 바코드의 정보량 제한을 해결하기 위해 가로, 세로 두 방향으로 정보를 기록할 수 있는 2 차원 바코드이다. $\mathrm{QR}$ 코드는 2차원으로 확장됨으로써 저장할 수 있는 정보량을 획기적으로 증가시킨 것이다 (Jang, 2011; Lee et al., 2011; Shin, 2012; Shim \& Go, 2012). 또한, 작은 공간에 인쇄할 수 있고, “오류 복원 기능”을 통하여 코드의 
일부가 더러워지거나 손상에도 데이터를 복원할 수 있을 뿐 아니라 고밀도의 데이터 표현, 데이터 암호화 기능, 및 360 도 어느 방향에서도 인식이 가능한 기능을 가지고 있다(Kim \& Lee, 2012; Yang, 2012).

이러한 장점을 갖는 $\mathrm{QR}$ 코드는 주로 상품의 포장지나 광 고지에 인쇄되고 있으며, QR코드를 스캔하면 해당 웹사이 트로 자동 접속되어, 제품에 대한 정보를 얻거나 할인 및 프로모션 이벤트에 참여할 수 있어 기업의 홍보 수단으로 많이 사용되고 있다. 최근 $\mathrm{QR}$ 코드는 위치기반서비스 (Located Based Service: LBS), 증강현실(Argument Reality:AR), 모바일 커머스(Mobile Commerce:MC)의 핵 심기술과 융합되어 적용이 증가하고 있으며 (Jung \& Choi, 2010; Lee \& Chung, 2011; Lee et al., 2011), 특히 광고, 판매 및 결재 등의 다양한 마케팅 수단으로 활용사례가 점 점 확대되고 있다(Jang, 2011; Kim et al., 2012).

\section{QR 코드 기반 가상패션점포}

1) 가상점포의 개념

가상점포(virtual store)는 실제 제품이나 서비스가 존 재하지 않는 가상공간에서 거래가 이루어지는 무점포 소 매점으로 인터넷 쇼핑, TV홈쇼핑, 모바일 쇼핑이 이에 해당된다. 이러한 가상 점포의 사례가 증가하면서 홈플

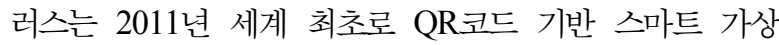
점포를 지하철 선릉역에 오픈했다. 이를 이어 북미, 유럽 시장에서도 $\mathrm{QR}$ 코드 가상점포의 개념이 확산되면서 온라 인과 오프라인이 결합된 '다중결합 4세대점포'로 3A(Anywhere, Anytime, Anyplace)쇼핑시대를 만들면서 유통시장이 점점 진화되고 있다(Carver \& Matus, 2012; Choi, 2011b; Jung, 2011; Song, 2012; "Top 10", 2013).

$\mathrm{QR}$ 코드 기반 가상점포란 스마트앱 기반 $\mathrm{QR}$ 코드를 활용한 가상공간에서 상품 또는 서비스의 거래가 이루지 는 공간을 말한다. 온라인과 오프라인의 장점을 결합한 멀티채널전략의 수단으로 스마트폰을 활용한 모델이라는 점에서 "스마트" 가상 점포로 구분되기도 한다(Song, 2012). QR코드 가상점포의 환경은 상품이 진열된 디지 털 디스플레이 스크린, 스마트폰 앱을 사용하는 QR코드 스캐너, 정보검색, 주문, 결제의 모바일 가상공간 정보시 스템으로 구성된다. 특히, 소매환경맥락에서 $\mathrm{QR}$ 코드 기 반 가상점포의 성공요인은 기술인프라를 통해 고객과의
상호작용성을 강화하여 쇼핑체험을 더욱 확대하는데 있 다. 소비자는 $\mathrm{QR}$ 코드를 통해 상세한 제품정보를 적극적 으로 탐색하고 구매시점에서 이벤트와 프로모션에 참여 함으로써 제품구매로 유도될 수 있다 (Shim \& Go, 2012).

2) $\mathrm{QR}$ 코드 가상패션점포 사례

최근 홈플러스의 스마트 가상 점포가 주목을 받자, 패 션기업들은 마케팅 수단으로써 $\mathrm{QR}$ 코드 기술을 적용한 " 스마트 가상점포"의 개념을 확대하고 있다. 국내의 구체 적인 사례를 살펴보면, "핀앤핏", "G마켓", "11번가", " 웨스트우드", "멋남" 등의 $\mathrm{QR}$ 코드를 적용한 가상점포의 사례가 있다(Kim et al., 2012; Song, 2012). 예를 들면, 2011년에 온라인 쇼핑몰 최초로 서울 지하철 명동역에 오픈한 가상 스토어 $\mathrm{G}$ 마켓은 홈플러스와 달리 패션 부 문을 특화한 새로운 개념의 가상 스토어이다. $\mathrm{G}$ 마켓 가 상 패션 스토어의 마케팅 컨셉은 디스플레이 스크린을 통해 간편하게 최신 패션 상품구색을 제공할 뿐 아니라 오프라인매장보다 저렴한 가격으로 판매를 촉진하고 있 다(Han, 2011; Song, 2012).

또한, SK 텔레콤은 매장에서 실제 제품들을 살펴보고 스마트폰으로 즉석에서 물건을 살 수 있는 $\mathrm{Q}$ 스토어 위 드 11 번가 $(\mathrm{Q}$ 스토어)를 본사에 두고, 고객들이 물리적 공 간의 $\mathrm{Q}$ 스토어 매장에서 스마트폰으로 제품에 스마트

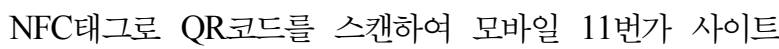
인 "가상공간"에서 구매할 수 있게 되어 있다. 이 $\mathrm{Q}$ 스토 어에서는 11 번가에서 엄선한 명품패션의류, 가전, 화장품 등 200 여개 다양한 상품을 갖추고 있는 것이 특징이다 (Whang, 2011).

패션 브랜드 핀앤핏(Pin \& Fit)은 홍대 패션거리에 $\mathrm{QR}$ 코드 팝업 가상스토어를 오픈하였다. 스마트폰으로 $\mathrm{QR}$ 코드를 스캔하면 직접 아이템에 대한 정보를 얻고 구 매할 수 있는 핀앤핏의 가상스토어는 건물 매장이 아닌 거리에 위치하고 있다. 이는 목표고객의 접근성을 고려 하여 브랜드의 상품아이템을 길을 오고가는 대중에게 쉽 게 소개하여 브랜드인지도를 높이고 있으며 이 매장은 이미 홍대거리의 명소로 떠오르고 있어 효과적인 마케팅 커뮤니케이션 수단으로 이용되고 있다(“Pin \& Fit”, 2012).

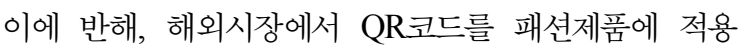


한 "스마트"가상 점포의 사례는 상대적으로 적다. 미국의 경우 쇼핑몰과 소매점에 $\mathrm{QR}$ 코드가 사용되고 있으며 (Carver \& Matus, 2012), 패션브랜드 캘빈클라인은 옥외 광고에 $\mathrm{QR}$ 코드 마케팅을 활용하여 지하철역, 건물, 퍼포 먼스 등 더 다양한 매체에서 $\mathrm{QR}$ 코드를 통해 신제품 영 상을 공개하여 실시간 광고효과를 얻고 있다(Lee \& Chung, 2011; Shim \& Go, 2012). 미국 시애틀에 있는 패션브랜드 “Hointer"는 청바지 $\mathrm{QR}$ 코드 무인점포로 적 은 매장의 규모로 다양한 상품을 취급하고 있을 뿐 아니 라 판매원 서비스 비용을 절감시켜 더 낮은 가격을 제공 할 수 있다. 또한 이 매장은 스마트 폰의 애플리케이션 을 통해 실시간 정보를 얻을 수 있어 고객지향적 브랜드 관리가 효과적으로 이루어지고 있다("No sales", 2012).

상기의 사례들을 살펴본 바와 같이, 마케팅 관점에서 $\mathrm{QR}$ 코드 가상패션점포는 젊은 소비자를 목표로 한 패션

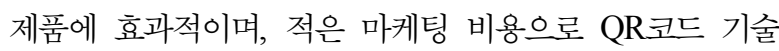
융합에 의해 특히 상품구색과 판촉전략 측면에서 마케팅 프로그램을 개발하는데 활용가치가 높을 것으로 예상된 다.

\section{QR코드 가상점포와 소비자 기술수용모델}

국내외 QR코드 가상점포와 관련된 실증적 연구들은 거 의 없는 실정이지만, 정보기술(IT)맥락에서 모바일과 디지 털 기술에 초점을 둔 대부분의 연구들을 살펴본 결과, Davis et al.(1989)의 기술수용모델(TAM)을 근거로 이론 적 토대를 마련하였고, 대부분의 연구들은 TAM의 지각된 유용성과 용이성이 기술수용의 결정적 예측변인으로 제시 되고 있다 (Bae, 2010; Ko et al., 2009; Oh et al., 2009; Venkatesh et al., 2003, 2012).

정보기술혁신의 초기연구에서는 정보시스템(information system)을 사용하는 실무자를 대상으로 TAM모델과 통합 한 UTAUT(Unified Theory of Acceptance and Use of Technology)모델을 제안했다(Venkatesh et al., 2003). UTAUT모델에 의하면 성과기대(performance expectancy), 노력기대(effort expectancy), 사회적 영향(social influence), 촉진조건(facilitating condition)의 구성요소가 소비자 기술사용의 행동의도에 유의한 영향을 준다고 밝혀 기술수용을 예측하는데 외재적 혜택요인의 중요성을 강조 하였다(Venkatesh et al., 2012).

모바일 인터넷 맥락에서는 소비자의 기술수용모델을 설
명하는데 혜택과 비용의 균형에 의한 거래 효율성 (transaction utility)을 강조하고 있다(Kleijnen et al., 2007). 이를 지지하는 Kim et al.(2007)의 연구에서는 VAM(value-based Adoption model)을 제시하고 모바일 인 터넷 수용에 대한 혜택과 희생이 가치에 미치는 영향을 밝 히고 있는데, 희생(sacrifice)요인인 기술성(technicality)과 지각된 비용(perceived fee)은 유용성(usefulness)과 즐거움 (enjoyment)과 같은 혜택요인보다 가치지각에 더 큰 영향 을 준다고 밝혔다. 기술성은 서비스를 제공하는 과정에서 기술적으로 우수한 정도로 (DeLone \& McLean, 1992), 기 술을 사용하는데 육체적, 심리적 노력이 들지 않는 기술성 을 지각할수록 수용의도를 증가시키는 반면, 경제적 비용을 지각할수록 수용 의도는 감소하였다(Kim et al., 2007). 이 러한 결과는 기술이 갖는 혜택 뿐 아니라 지각된 위험요소 는 신기술 수용의도를 예측하는데 매개변인으로서 중요한 역할을 하고 있음을 시사하고 있다. 이를 지지하는 Venkatesh et al. (2012)의 연구에서는 기술수용의도를 예 측하는데 소비자의 쾌락적 동기(hedonic motivation)와 가 격가치(price value)요소가 추가되어 소비자 관점에서 통합 된 기술수용모델을 제시하였다.

가상점포맥락에서의 연구들을 살펴보면 Oh et al.(2009) 는 TAM모델을 근거로 인터넷 기반 온라인 가상스토어를 초점으로 유용성과 용이성뿐 아니라 풍부한 정보력에 의한 즐거움(playfulness)이 가상점포의 수용태도에 중요한 역할 을 하고 있음을 밝혔다. 이를 지지하는 Ko et al.(2009)는 모바일 쇼핑에 대한 유용성, 용이성, 즐거움이 패션제품에 대한 구매의도를 증가시키고 있음을 제시하였다. 더욱 최근 에는 모바일 앱스토어를 초점으로 TAM모델을 적용한 연 구에서는 지각된 유용성과 용이성이 모바일 앱스토어의 수 용의도를 증가시킨다고 밝혔다(Bae, 2010; Kim \& Jeon, 2011).

이상의 선행연구를 고찰해 본 결과, 온라인에서 모바일 맥락까지 기술수용모델이 실증적으로 검증되고 있으나 $\mathrm{QR}$ 코드 가상점포맥락에서 기술수용모델을 검증한 연구는 아 직까지 이루어지지 않고 있다. 선행연구들에서 제시된 지각 된 용이성과 유용성이 $\mathrm{QR}$ 코드 기반에서도 마찬가지로 수 용의도를 높일 수 있는 혜택요인으로 작용할 수 있다. 그러 나 사용자 관점에서 혁신단계에서의 신기술 시스템을 이용 하는데 드는 복잡성에 의한 불확실성 뿐 아니라 심리적, 경 제적 비용은 기술수용을 지연시키거나 방해하는 요인이 될 수 있을 것이다. 따라서 $\mathrm{QR}$ 코드 기반 디지털 기술을 적용 한 점포는 기존 쇼핑의 공간과 시간의 개념을 파괴한 혁신 
적 유통채널이라는 점에서(Han, 2012; Lee et al., 2011; Song, 2012) QR코드가 신기술로 인식되는 초기단계에 소 비자의 수용가능성을 예측하기 위해서 QR코드 가상점포에 대한 지각된 혜택과 위험 요인을 동시에 고려할 필요가 있 다고 본다.

\section{III. 연구 방법}

\section{1. 연구문제}

본 연구는 기술수용모델을 바탕으로 탐색적 접근을 통 해 신기술로서의 $\mathrm{QR}$ 코드 기반 가상패션점포에 대한 소 비자의 수용가능성을 진단하기 위해 다음과 같은 연구문 제를 설정하였다.

연구문제 1. 소비자는 $\mathrm{QR}$ 코드 기반 가상점포를 어떻 게 인식하고 있는지 파악한다.

연구문제 2. QR코드 가상패션점포에 대한 지각된 혜 택요인을 탐색하여 소비자 수용의도를 증가시키는 결정적 요인을 파악한다.
연구문제 3. $\mathrm{QR}$ 코드 가상패션점포에 대한 지각된 위 험요인을 탐색하여 소비자 수용의도를 감소시키는 저해 요인을 파악한다.

\section{FGI 패널 선정}

본 연구의 패널은 변화를 추구하여 신기술 수용력이 높으며 최근 스마트폰을 사용하고 있는 20대 남녀소비자 로 선정하였다. 패널선정의 기준은 최근 $\mathrm{QR}$ 코드 기반 가상점포(홈플러스, 핀앤핏, 11 번가)에 대한 경험을 가지 고 있는 남녀소비자로서 유사한 조건을 가진 사람을 제 안 받는 눈덩이 표집(snowball sampling)을 병행하여 21 명을 선정하였다. 선정된 패널은 자발적으로 참여에 동 의하였으며 총 21 명을 3 개 집단(집단 $1=6$ 명, 집단 $2=7$ 명, 집단 $3=8$ 명)으로 나누어 면접을 진행하였다.

각 집단별 면접대상자의 일반적 특징을 살펴보면 <Table 1>과 같이 여성 17 명과 남성 4 명으로 구성되었 다. 면접대상자의 연령분포는 20-25세의 범위에 있는 대 학생으로 평균연령은 22.5 세였다. 스마트폰 사용기간은

〈Table 1〉 FGI Panels' Characteristics

\begin{tabular}{|c|c|c|c|c|c|}
\hline Focus Group & Panels & Gender & Age & Experience with $Q R$ virtual store & Resident area \\
\hline Group 1 & $\begin{array}{l}\text { Panel1 } \\
\text { Panel2 } \\
\text { Panel3 } \\
\text { Panel4 } \\
\text { Panel5 } \\
\text { Panel6 }\end{array}$ & $\begin{array}{l}\text { Female } \\
\text { Female } \\
\text { Female } \\
\text { Female } \\
\text { Female } \\
\text { Female }\end{array}$ & $\begin{array}{l}21 \\
20 \\
20 \\
21 \\
21 \\
22\end{array}$ & $\begin{array}{c}\text { Pin \& Fit, Home plus } \\
\text { Pin \& Fit, Home plus } \\
\text { Home plus } \\
\text { Home plus } \\
\text { Pin \& Fit } \\
\text { Pin \& Fit, Home plus }\end{array}$ & $\begin{array}{c}\text { Seoul } \\
\text { Seoul } \\
\text { Incheon } \\
\text { Seoul } \\
\text { Seoul } \\
\text { Seoul }\end{array}$ \\
\hline Group 2 & $\begin{array}{c}\text { Panel7 } \\
\text { Panel8 } \\
\text { Panel9 } \\
\text { Panel10 } \\
\text { Panel11 } \\
\text { Panel12 } \\
\text { Panel13 }\end{array}$ & $\begin{array}{c}\text { Male } \\
\text { Female } \\
\text { Male } \\
\text { Male } \\
\text { Male } \\
\text { Female } \\
\text { Female }\end{array}$ & $\begin{array}{l}22 \\
23 \\
21 \\
24 \\
23 \\
22 \\
21\end{array}$ & $\begin{array}{c}\text { Pin \& Fit } \\
\text { Pin \& Fit, Home plus } \\
\text { Pin \& Fit, Home plus } \\
\text { Pin \& Fit, Home plus } \\
\text { Pin \& Fit, Home plus } \\
\text { Pin \& Fit, Home plus } \\
\text { Pin \& Fit, Home plus }\end{array}$ & $\begin{array}{l}\text { Gyeonggi } \\
\text { Gyeonggi } \\
\text { Gyeonggi } \\
\text { Gyeonggi } \\
\text { Gyeonggi } \\
\text { Gyeonggi } \\
\text { Gyeonggi }\end{array}$ \\
\hline Group 3 & $\begin{array}{l}\text { Panel14 } \\
\text { Panel15 } \\
\text { Panel16 } \\
\text { Panel17 } \\
\text { Panel18 } \\
\text { Panel19 } \\
\text { Panel20 } \\
\text { Pane21 }\end{array}$ & $\begin{array}{l}\text { Female } \\
\text { Female } \\
\text { Female } \\
\text { Female } \\
\text { Female } \\
\text { Female } \\
\text { Female } \\
\text { Female }\end{array}$ & $\begin{array}{l}23 \\
24 \\
24 \\
24 \\
23 \\
24 \\
24 \\
25\end{array}$ & $\begin{array}{c}\text { Pin \& Fit, Homeplus } \\
\text { Pin \& Fit, Home plus } \\
\text { Pin \& Fit, } 11^{\text {th }} \text { Street } \\
\text { Pin \& Fit, } 11^{\text {th }} \text { Stree } \\
\text { Pin \& Fit, Home plus } \\
\text { Pin \& Fit, } 11^{\text {th }} \text { Street } \\
\text { Pin \& Fit } \\
\text { Pin \& Fit }\end{array}$ & $\begin{array}{l}\text { CheongJu } \\
\text { Gyeonggi } \\
\text { CheongJu } \\
\text { CheongJu } \\
\text { Gyeonggi } \\
\text { CheongJu } \\
\text { CheongJu } \\
\text { CheongJu }\end{array}$ \\
\hline
\end{tabular}


6-36개월로 평균 19.5 개월이었으며, 전화통화, 인터넷 검 색 및 $\mathrm{SNS}$ 를 목적으로 대부분 사용하고 있는 것으로 나 타났다. 또한, 면접대상자 중 13명(61.9\%)이 스마트폰을 활용한 모바일 쇼핑경험이 있는 것으로 나타났으며, 구 매한 상품으로는 의류, 화장품, 영화티켓, 쿠폰, 공연, 외 식상품권이었다.

\section{3. 표적집단면접 $(\mathrm{FGl})$ 의 질문내용과 절차}

FGI는 2012년 7 9월 중에 집단별 1회 실시되었으며, 연구자가 사회자로 참여하여 진행되었다. 주제에 대한 면접내용은 일반적 질문에서 구체적 질문의 순으로 단계 적으로 제시되었다. 면접의 초기단계에서는 일상에 관한 대화를 통해 면접대상자와의 친밀감을 형성하고 편안한 상태로 응답할 수 있도록 하였다. $\mathrm{FGI}$ 의 일반적 질문단

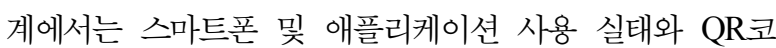
드 가상점포에 대한 전반적인 인식을 파악하고자 하였으 며, 구체적 질문단계에서는 $\mathrm{QR}$ 코드 가상점포에 대한 기 술과 비즈니스 속성에 대한 긍정적 부정적 경험과 패션 제품에 초점들 둔 $\mathrm{QR}$ 코드 가상점포에 대한 소비자 반응 을 유도하고자 하였다. 질문의 주요내용은 <Table 2>와 같다. 면접에 소요된 시간은 1 시간 30 분-2시간동안 이루 어졌으며, 면접대상자에게는 연구에 참여한 사례비(2만 원)가 제공되었다. 인터뷰중의 모든 대화내용을 정확하게 유지하기 위해 면접대상자의 동의하에 인터뷰 전 과정이 녹취되었다.

\section{4. 자료분석방법}

자료분석을 위해 면접 후 녹취된 내용은 하나도 빠짐 없이 그대로 전사되었으며 총 1,044 문장의 응답이 도출되

〈Table 2〉 FGI procedure and questions
었다. 자료분석은 Nvivo 2.0프로그램을 이용하여 전사된 내용을 연구문제에 따라 범주화하기 위해 묘사 (description)단계를 코딩하고 범주에 따른 내용의 일반화 (generalization)와 해석(interpretation)단계에서 일관성과 응답빈도에 근거하여 속성을 도출하는 내용분석(content analysis)을 수행하였다. 내용분석의 타당성을 위해 범주 별로 공동연구자가 각각 분석한 내용 중 일치하지 않는 항목을 제거한 후 합의된 내용을 최종결과로 사용하였 다.

\section{IV. 결과 및 논의}

\section{1. 소비자의 $Q R$ 코드기반 가상점포에 대한 인식}

소비자의 $\mathrm{QR}$ 코드 가상점포에 대한 인식을 파악하기 위 해 가상점포에 대한 인식 또는 경험과 관련된 토론 내용을 분석한 결과, $\mathrm{QR}$ 코드 가상점포에 관하여 대부분의 응답자 들은 대중교통을 이용하다가 접해본 경험이 있거나 대중매 체를 통해 들어본 적이 있다고 언급하고 있다. 특히, 스마 트 가상점포의 특징으로 오프라인으로 제시된 상품이나 광 고판에 있는 $\mathrm{QR}$ 코드를 스캔해서 가상공간에서 제품을 구 매할 수 있는 개념으로 인식하고 있다.

"인터넷 기사로 들어봤어요...버스정류장에서 먼 저 접했던 것 같애요... 원래는 광고판 들어가는 덴데 거기 바코드가 있고, 물건들이 있더라구요...뭐지?하 고 보니깐 가상점포라고 되어 있었어요." (패널6)

"남성복인지 캐쥬얼 룩인지는 모르겠는데 남성복 의류매장에 택에 $\mathrm{QR}$ 코드가 있대요...그걸로 찍어보고 서 알아보고 구매도 바로 할 수 있다고..작년에 런칭 했다는 기사를 본적이 있었어요." (패널3)

\begin{tabular}{ll}
\hline Step 1. & Introduction \& general exploratory discussion \\
& Smart phone usage; level of experience and perception of QR code virtual store \\
\hline Step 2. & Detail exploratory discussion 1 \\
& $\begin{array}{l}\text { Experienced with technological or business attributes of } \mathrm{QR} \text { code based stores } \\
\text { Good or bad experiences at } \mathrm{QR} \text { code virtual fashion stores }\end{array}$ \\
\hline Step 3. & Detail exploratory discussion 2 \\
Step 4. & Intent to use QR code virtual store for purchasing fashion products or brands \\
\hline
\end{tabular}


한편, QR코드기반 가상점포에 대한 인식은 일반적인 온 라인 가상점포 또는 모바일 가상점포와는 차별화된 3차원 가상공간에서 제품을 탐색하고 구매, 결제까지 가능한 쇼핑 공간으로 지각하고 있었다. 특히, 패션제품과 관련하여 가 상현실의 기술을 활용하여 개인의 체형과 이미지에 맞는 제품을 구매할 수 있는 개인화된 시스템으로 인식하고 있 다.

\footnotetext{
"처음에 생겼을 때요 그때 TV를 보고서는 아 저 게 가상스토어구나 그렇게 알게 되었는데 제가 생각 했었던 가상스토어는 뭐 사람이 이렇게 들어가 서...3D로 스캔하고 그런것 인줄 알았는데...." (패널 17).

"가상 스토어 같은 경우에 진짜 제가 실제로 가지 않고 그냥 어디 가정이나 길거리 가는데 스크린 같 은게 있으면 스크린 자체에서 내가 저걸 보고 아 마 음에 든다 하면 구매가 가능한 거 이런식으로 생각 을 했어요...." (패널18).
}

이와 같이 스마트 가상점포에 대한 응답내용들은 사용자 가 언제어디서나 스크린의 제품에 대한 정보를 얻을 수 있 는 QR코드의 “위치기반서비스", 또는 3차원 가상공간에서 실제 환경에 존재하는 것처럼 보여주는 “증강현실”이 융합 된 디지털 기술과 구매나 결제가 가능한 “모바일 커머스" 기능들과 같이 인식되고 있다. 이러한 결과는 선행연구들이 제시하고 있는 $\mathrm{QR}$ 코드와 연동된 디지털 기술융합을 반영 하면서 $\mathrm{QR}$ 코드 기술이 갖는 고유의 특징이 점포맥락에서 인식되고 있음을 시사하고 있다(Jung \& Choi, 2010; Kim et al., 2012; Lee et al., 2011).

\section{QR코드 가상패션점포의 지각된 혜택}

$\mathrm{QR}$ 코드 가상점포에 대한 FGI내용의 분석과정에서 $\mathrm{QR}$ 코드 가상점포에 대한 지각된 혜택과 위험과 관련된 총 178 응답문구가 추출되었다. 먼저 지각된 혜택요소를 탐색하기 위해 $\mathrm{QR}$ 코드 가상점포경험에 대해 긍정적으로 응답한 79개의 문구를 분류하고, 응답내용에 따라 QR코 드 기반 기술과 비즈니스 측면에서 다시 하위 속성을 분 석한 후, 내용의 일관성에 따라 혜택요인으로 범주화하

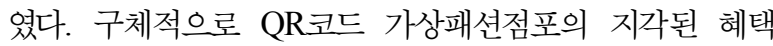
에 관한 응답내용을 분석한 결과, <Table $3>$ 에 나타난 바와 같이 “감성적 소구” “지각된 유용성," "편재성", “브랜드 홍보”의 4개의 하위요소로 분류되었다.
1) 감성적 소구

가장 많이 언급된 $\mathrm{QR}$ 코드 패션가상점포의 지각된 혜 택은 "감성적 소구"차원이다. 이는 $\mathrm{QR}$ 코드 가상점포에 대한 호기심 유발과 시각적 소구에 관한 내용으로 선행 연구에서 제시되고 있는 기술의 쾌락적 속성과 유사한 요인임을 알 수 있다(Ko et al., 2009; Oh et al., 2009; Venkatesh et al., 2012). 응답자들은 QR코드 가상점포 의 시각적으로 제시된 상품의 디스플레이 스크린 (Display screen)을 보고 신기하여 호기심이 유발되고 있 음을 알 수 있다. 또한, 실물로 제시된 상품이 아님에도 불구하고 상품사진이 실물이미지와 너무 똑 같고 예뻐서 눈길이 간다는 내용으로 예를 들면 다음과 같다.

"그게 딱 처음에 봤을 때 시선을 사로잡는 것 같 아요. 처음에 모르고 보았을 때 우와 이거 뭐지 하면 서 대부분 사람들이 쳐다보는 것 같아요." (패널14)

"상수역 쪽으로 걸어가면 옷가게 쪽 있는데, 거의 비슷비슷하잖아요, 그런데 이제 벽면색깔이 너무 강 렬하잖아요, 강렬하니깐 좀 사람 이끌기에는 좋았던 것 같고, 가장 좋았던 것은 진짜 아까도 말했듯이 옷 다 그려져 있는 거여요." (패널17).

2) 지각된 유용성

두 번째로 자주 언급된 "지각된 유용성" 차원은 쇼핑 의 유용성, 에너지 또는 시간의 효율성, 주문/배달 서비

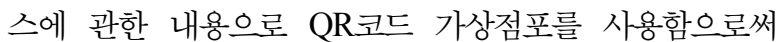
얻는 성과기대(performance expectancy)에 대한 혜택을 지각하고 있다. 응답내용을 살펴보면, $\mathrm{QR}$ 코드 가상점포 는 대부분 쉽게 접할 수 있는 위치에 있어 직장인이 출 퇴근할 때 이용가능하기 때문에 시간과 노력비용을 줄일 수 있다는 내용을 언급하고 있다.

"집에 가면 피곤해서 자게 되고, 장보러가는 것도 귀찮고, 회사에서는 눈치 보이니깐 컴퓨터로 쇼핑할 시간이 없었는데 지하철 기다리면서 사면되겠다, 편 하겠다고 생각했어요." (패널2)

"직장을 다니는 사람이라면, 출근길에 주문해 놓 고 퇴근길에 오면 받을 수 있고, 그게 편할 것 같아 요." (패널14)

3) 편재성

$\mathrm{QR}$ 코드 가상점포에 대한 혜택의 "편재성"차원은 시공 
간을 초월하여 언제 어디서나 고객이 원하는 시점에서 즉각적으로 정보를 얻을 수 있는 개념 (Jang, 2011; Lee \& Kim, 2011)을 내포하고 있다. 응답내용은 즉각적으 로 무선 인터넷 사이트로의 연결가능성과 원하는 상품정 보를 실시간 접근 가능성의 내용을 포함하고 있는데 이 는 $\mathrm{QR}$ 코드 기술이 융합된 위치기반 서비스 속성을 잘 반영해주고 있다.

"QR코드로 많은 제품을 지나가다 구매가 아니더 라도 궁금증에 정보같은 것은 링크해서 볼 수 있을 것 같아요." (패널9)

"접근성이 더 빠른 것 같아요 시간도 그렇고 공간 적인 것도 제약이 없잖아요. 그런 점에서 되게 빨리 진행할 수 있어서 컴퓨터는 부팅시간이 오래걸리는 데 그런것 따로 없이 딱 눌러서 들어가서 바로 할 수 있으니깐 그런게 되게 ...메뉴가 간편하게 잘 되어있 어요." (패널 18)

4) 브랜드 홍보

$\mathrm{QR}$ 코드 가상점포의 또 다른 혜택은 비즈니스 측면에 서 “브랜드 홍보”로서 소비자로 하여금 브랜드나 기업의 이미지를 노출시킬 수 있는 광고효과를 가지며 이를 통 해 소비자는 브랜드 인지도를 높일 수 있다. 특히, 패션 브랜드의 경우 디스플레이 스크린을 통해 시각적으로 고 유의 이미지를 소구할 뿐 아니라 신기술을 사용하는 진 취적인 이미지로 인식되고 있음을 언급하고 있다.

"굉장히 장점 같아요. 노출도가 높을 수 있잖아 요, 여러 군데서. 굳이 옷 같은 경우도 진짜 단골 매 장이나 맘에 드는 매장이 있어서 찾아가는 경우도
있지만 지나가다 예쁜 옷 볼 수도 있는 경우도 있거 든요." (패널9)

"OOO 같은 경우 의류가 캐릭터 티셔츠고 젊 은 분위기,위치도 홍대고 거기다 젊은 친구들이 가지고 있는 스마트폰을 도구로 해서 지나가는 모든 사람들이 그 바코드를 찍는건 아니지만...... 그 브랜드가 모바일을 이용한 것 때문에 젊음을 추구하는 진취적인 이미지의 브랜드 이런 선입견 이 생겼어요." (패널2)

이와 같이, $\mathrm{QR}$ 코드 기반 가상점포 맥락에서 지각된 혜택요인은 "지각된 유용성"과 "편재성"과 같이 $\mathrm{QR}$ 코드 기술과 연결된 외재적 혜택(extrinsic benefit)을 지지할 뿐 아니라 (Kleijnen et al., 2007) "감성적 소구"와 "브 랜드 홍보"의 내재적 혜택(intrinsic benefit)을 포함하고 있다 (Kim et al., 2007; Ko et al., 2009). 특히, 패션제 품의 경우, 가상공간이 아닌 물리적인 공간에 있는 상품 의 디스플레이 보드나 광고 스크린을 통한 감성적 소구 가 가장 현저하게 나타나 소비자 수용의도에 중요한 역 할을 하고 있음을 예측할 수 있다. 이러한 결과는 $\mathrm{QR}$ 코 드와 함께 상품 디스플레이 스크린은 전통적인 점포 분 위기를 향상시키는 것과 같은 효과로서 감성적 반응을 유도하여 소비자가 신기술 $\mathrm{QR}$ 코드 가상점포에 쉽게 접 근할 수 있게 유도할 수 있을 것이다.

$\mathrm{QR}$ 코드 가상패션점포 맥락에서도 지각된 유용성은 기 존의 기술수용모델과 일치한 결과로(Bae, 2010; Davis, 1989; Kim et al., 2007; Venkatesh et al., 2012), 소비 자의 수용가능성을 진단하는데 결정적인 혜택요인임을 지지하였다. 그러나 기존의 모바일 가상스토어에 비해 $\mathrm{QR}$ 코드 기반 가상점포는 모바일 앱과 연동한 실시간 상

〈Table 3〉 Content analysis of perceived benefits QR code virtual fashion store

\begin{tabular}{|c|c|c|}
\hline Perceived Benefit Factors & Attributes (Frequency) & $\begin{array}{c}\text { Total number } \\
(\%)\end{array}$ \\
\hline Affective appeal & $\begin{array}{l}\text { Evoking anxious or emotional reaction (19) } \\
\text { Visual appeal(14) }\end{array}$ & $33(42 \%)$ \\
\hline Perceived usefulness & $\begin{array}{l}\text { Enhancing shopping performance }(8) \\
\text { Delivery service }(6) \\
\text { Time efficiency }(6)\end{array}$ & $20(25 \%)$ \\
\hline Ubiquity & $\begin{array}{l}\text { Instant connectivity (10) } \\
\text { Instant accessibility to information (4) }\end{array}$ & $14(18 \%)$ \\
\hline Brand promotion & $\begin{array}{l}\text { Brand image and advertising effect (10) } \\
\text { Corporate image (2) }\end{array}$ & $12(15 \%)$ \\
\hline Total & 9 attributes & $79(100 \%)$ \\
\hline
\end{tabular}


호작용성을 더욱 활성화시킬 수 있는 점에서(Jang, 2011; Lee et al., 2011; Lee \& Chung, 2011; Lee \& Kim, 2011 ) 출퇴근시간이나 대중교통장소의 쇼핑 상황을 적용 한 $\mathrm{QR}$ 코드 가상점포의 유용성과 편재성에 대한 지각에 차이점을 보이고 있다.

\section{QR코드 가상패션점포의 지각된 위험}

$\mathrm{QR}$ 코드 가상점포에 관한 지각된 위험에 관한 내용은 전체 178 개의 응답문구 중 99 개의 응답문구(55.6\%)가 분석되었다. $\mathrm{QR}$ 코드 패션가상점포의 지각된 위험은 정 보기술측면의 시스템을 이용하여 상품을 구매하는 과정 의 비즈니스 측면에서 $\mathrm{QR}$ 코드 가상패션점포에 대해 부 정적으로 인식하고 있는 내용을 포함하고 있었다. 구체 적으로 지각된 위험요소를 밝히기 위해 응답내용을 기술 적 측면과 비즈니스 측면에서 하위속성으로 분석한 후 내용의 일관성에 따라 위험요인으로 범주화하였다. <Table 4>에서 제시된 바와 같이 지각된 위험은 "사용 의 복잡성," "제품정보제한", "기술 인프라 부족" "지각 된 비용"의 4 개 차원으로 분류되었다.

\section{1) 사용의 복잡성}

가장 많이 응답빈도를 보인 "사용의 복잡성"은 신기술 을 이용하는데 비교적 어렵다고 지각된 정도로서 (Thompson et al., 1994) QR코드를 스캔해야 하는 부가 적인 과정의 불필요성, 구매결제를 위한 절차의 복잡성, 회원가입 요구에 대한 불편성에 관한 내용을 포함하고 있다. 이 속성은 Davis et al.(1989)가 제시한 지각된 유 용성과 Venkateh et al.(2003)의 노력기대(effort

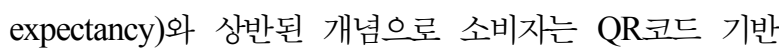
가상점포를 이용하기가 쉽지 않다고 지각하고 있었다.

"QR코드를 찍을려면 앱을 다운 받아야되고 설치 를 하고 다시 또 바코드를 찍으면 회원가입을 또 해 야되고..이렇게해서 구매하려면 또 신용카드 정보까 지 넣어야되고 이게너무 복잡하고 느리고 아직은 좀 불편했던 것 같애요." (패널1)

"결제를 눌렀는데 회원가입을 하라고 나와서 비 회원으로 들어갔어요. 그래서 다 쳤어요. 배송지를 치는데 우편번호 검색을 해서 안 넘어가는 거에요. 치려고 했는데 치는 것도 안되요. 그래서 그냥 거기 에 막혀서, 결제는 못했는데, 저는 사이트를 왜 그렇
게 했는지를 도대체..." (패널 21)

2) 제품정보제한

두 번째로 자주 언급된 $\mathrm{QR}$ 코드 가상점포의 위험지각 은 "제품정보제한"으로 구매하기 위한 정보탐색과정에서 디스플레이 스크린에 진열된 상품구성이 부족하거나 비 교 쇼핑하기에 상품정보가 부족하다고 인식하고 있었다. 특히, 패션제품의 경우 고객이 원하는 상품구색이나 정 보의 개별화가 잘 되어 있지 않아 개인에게 중요한 속성 을 평가하기 어려워 구매 결정에 대한 위험을 지각하고 있었다.

"상품량도 너무 적어서...한 10 개 정도, 10 개 미만 정도 되는 것 같은데" (패널14).

"단점은 아까 말했듯이 저는 사이트 여러 개를 켜 놓고 엄청 비교하면서 사거든요 근데 그거는 몇 개 제품밖에 없다는 게 아쉬운 것 같아요." (패널11)

"일단 자기한테 맞는 스타일을 찾는다 해도 맞을 지 모르고 사이즈도 맞을지 모르니까 그런게 좀 불 편했던 것 같아요. 그런 편리, 구매하고 하는건 좋은 데 직접적으로나 의류나 이런 것 같은 경우에는 내 가 맞는 좋아하는 스타일을 잘 찾을 수 없다는 생각 이 들었어요. 그런게 좀 있었어요." (패널16)

\section{3) 기술 인프라 부족}

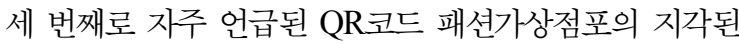
위험은 "기술 인프라 부족"으로 시스템을 사용하는데 무선 통신(Wifi) 또는 모바일 디바이스와의 인터페이스 (interface)측면에서 사용하기에 불편하다고 응답하고 있다. 자주 언급된 내용으로는 $\mathrm{QR}$ 코드를 스캔하고 모바일 스크 린을 통해 정보를 제공받는 과정에서 업체의 가상점포를 위한 쇼핑인터페이스 개발이 미흡하여 화면을 늘리고 줄이 고 해야 하는 사용의 불편성으로 나타났다. 속도나 모바일 웹 화면의 문제는 일반적으로 스마트폰을 이용한 모바일 인터넷 서비스에 해당하는 문제점과 같은 맥락이지만 본 연구 결과는 $\mathrm{QR}$ 코드 스캔 후 해당 쇼핑몰이나 기업의 홈 페이지로 연결되는 인터페이스 측면에서 $\mathrm{QR}$ 코드의 핵심가 치를 적극적으로 활용하지 못하여 발생하는 문제점이라고 본다. 이러한 속성은 혁신기술의 호환성(compatibility)측면 에서(Moore \& Benbasat, 1991), 아직까지 QR코드 시스템 으로 지지하는데 기술력이 부족함을 반영하고 있다. 
"또 밑으로, 제가 없는 걸 찍었을지는 모르지만, 상품평도 없었고, 또 주의 사항도 읽을 경우에도 피 씨 화면처럼 내려와서 잡아서 또 내려야 하고 줄여 서 또 내려와야 하고 그런게 불편했어요." (패널1)

"모바일 페이지로 결제가 바로 넘어갈 줄 알았는 데.... 중간에 정보 같은것도 잘 안보여서 쭉 늘려서 이렇게, 이렇게 읽고 다시 넘어가야 하는게 제일 불 편했어요. 그럴바엔 $\mathrm{OOO}$ 블로그가 있거든요. 블로 그 가서 옷을 보고 거기서 오히려 결제를 하면 빠를 것 같다라는 생각을 했어요." (패널17)

또한, 소비자 관점에서 가상점포를 사용하는데 무선인프 라에 대한 기술이 미흡하여 인터넷 속도나 연결에 대한 문 제점이 지적되고 있다. 이러한 속성은 선행연구에서 제시된 기술수용에 영향을 주는 촉진조건(facilitating condition)과 관련하여(Thompson et al., 1994; Venkatesh et al., 2003) 고객으로 하여금 $\mathrm{QR}$ 코드를 통해 가상점포로의 쇼핑을 촉 진시키지 못하고 있음을 보여준다. 이는 현재 Wifi 또는 $3 \mathrm{G}$ 기술 인프라 부족으로 스마트폰으로 활용한 모바일 인 터넷 서비스와 연결된 문제점이기도 하며, 고객접점에서 모 바일 가상점포공간으로 바로 연결해주는 QR코드의 기능을 충분히 살리지 못하고 있음을 반영하고 있다.

"강남역이라던지 압구정이라던지 번화가로 $\mathrm{QR}$ 코드 시스템이 들어가게 되면 사실 지금도 강남역에 서 $3 \mathrm{G}$ 데이터가 잘 안터지는데 그게 과연 아무리 LTE가 지금 빠르다고 해도 사용자가 늘어나게 되면 과부하가 되서 지금보다 분명히 느려질텐데 그러면 이게 빠른 쇼핑이 장점인데 그 장점을 계속 유지할 수 있을까하는 생각이 들어요." (패널13)

4) 지각된 비용

$\mathrm{QR}$ 코드 가상점포의 "지각된 비용"은 기술을 사용하기 위해 소요되는 경제적 또는 비경제적 비용의 개념이다. 응답내용을 구체적으로 살펴보면, 비경제적 측면에서는 가상점포가 특정장소에만 국한되어 위치하고 있기 때문 에 직접 점포를 가야 하는 것이 귀찮다고 느끼고 있어, 이용하는데 드는 시간과 노력을 지각하고 있었다. 이러 한 요인은 $\mathrm{Kim}$ et al.(2007)이 제시한 지각된 희생 (perceived sacrifices)개념과 일치하는 내용으로 특별한 시스템을 이용하는데 드는 신체적, 정신적 노력을 지지 하고 있다. 이러한 비경제적 비용은 기술수용모델에서 제시되고 있는 “용이성(ease of use)”의 상반된 개념으로 (Davis et al., 1989), QR코드 가상점포의 수용에 위험요
소로 작용하고 있음을 알 수 있다.

$$
\begin{aligned}
& \text { "솔직히 귀찮았어요. 찾아가서 찍고.." (패널10) } \\
& \text { "제가 발품을 팔아서 그 위치로 가면 직접 제가 } \\
& \text { 그 물품을 바로 얻을 수 있는 그런 장점 때문에 갈 } \\
& \text { 확률이 높은데 거기 같은 경우는 찍어서 새롭게 또 } \\
& \text { 주문해야 되는 거라면 말씀하신 것처럼 좀 수고스럽 } \\
& \text { 고 귀찮지 않을까 하는 생각을 했어요." (패널12) }
\end{aligned}
$$

지각된 비용은 특히 패션제품을 구매할 경우 경제적 측면에서도 가격에 대한 위험지각을 하고 있는 것으로 나타났다. 응답자들은 제품가격을 인터넷과 비교하고 있 으며, 인터넷보다 가격이 높거나 할인혜택이 적다고 인 식하고 있었다. 이러한 요소는 $\mathrm{Kim}$ et al.(2007)이 제시 한 지각된 비용(perceived fee)이 지각된 가치와 부적 상 관을 갖는다는 결과를 지지하면서 지각된 경제적 위험은 $\mathrm{QR}$ 코드 패션가상점포의 수용의도를 감소시킬 수 있음을 시사한다.

\footnotetext{
"막상 $\mathrm{OOO}$ 사이트에 들어가면 현재 가상스토어 에 있는 $\mathrm{OOO}$ 의 옷이 살짝 비싼 가격대에요, 사이트 에 들어가면 19,000 원에서 20,000 얼마짜리도 있더 라고요, 굳이 이렇게 비싼, 아무리 이제 좋은 신상품 을 선별했다고 하더라도..." (패널20)

"네, 되더라고요. 그렇게까지 크지는 않고, 좀 실 망을 했어요, 몇 \%된다 해가지고 추가할인 되는 줄 알았는데 그런 것도 없고..." (패널16)
}

이와 같이, $\mathrm{QR}$ 코드 가상패션점포 맥락에서 지각된 위 험요소는 신기술 시스템을 사용하고 구매를 위한 거래과 정에서 인식되고 있다. 거래과정에서 지각된 위험은 "복 잡성"과 "제품정보제한"에 대한 내용으로 특히 가장 많 이 언급된 복잡성은 TAM의 용이성(ease of use)과 상반 된 개념이다(Bae, 2010; Kim \& Jeon, 2011). 또한, "기 술 인프라 부족”과 “지각된 비용”은 신기술을 사용하는 데 육체적, 심리적 노력이 들지 않는 기술성(technicality) 과 상반된 개념으로 수용의도가 증가한다는 관점을 지지 하지 못하고 있다(DeLone \& McLean, 1992).

한편, 구매거래과정에서 지각된 경제적 비용은 수용의 도를 감소시킨다는 선행연구를 지지할 뿐 아니라(Kim et $a l ., 2007)$, 제품정보제한은 대안평가과정에서 지각된 위 
〈Table 4〉 Content analysis of perceived risks for QR code virtual fashion store

\begin{tabular}{|c|c|c|}
\hline $\begin{array}{l}\text { Perceived Risk } \\
\text { Factors }\end{array}$ & Attributes (Frequency) & Total number (\%) \\
\hline Complexity & $\begin{array}{l}\text { Reluctance to scanning QR code (17) } \\
\text { Complexity of transaction procedure (11) } \\
\text { Membership required (10) }\end{array}$ & $38(36 \%)$ \\
\hline Lack of product information & $\begin{array}{l}\text { Limited merchandise assortment (9) } \\
\text { Lack of information for comparison shopping(16) }\end{array}$ & $25(24 \%)$ \\
\hline $\begin{array}{l}\text { Lack of technology } \\
\text { infrastructure }\end{array}$ & $\begin{array}{l}\text { Incompatible to mobile device (11) } \\
\text { Poor wireless infrastructure (8) } \\
\text { Poor screen display or layout (4) }\end{array}$ & $23(22 \%)$ \\
\hline Perceived cost & $\begin{array}{l}\text { Physical or mental efforts }(13) \\
\text { Perceived price }(6)\end{array}$ & $19(18 \%)$ \\
\hline Total & 10 attributes & $105(100 \%)$ \\
\hline
\end{tabular}

험으로서 소비자를 구매로 이끌지 못하고 있음을 알 수

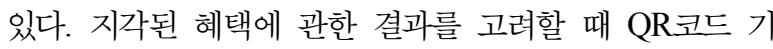
술에 의해 유용성과 편재성의 혜택이 제공됨에도 불구하 고 구매시 정보처리과정에서 발생된 지각된 비용은 소비 자의 수용의도를 저해할 수 있을 것으로 예측된다. 따라 서 소비자의 수용가능성을 높이기 위해 구매결정과정에 서 지각된 혜택과 동시에 위험요인을 고려하여 $\mathrm{QR}$ 코드 가상 점포 환경을 향상시켜야 할 것이다.

\section{$\mathrm{V}$. 결론 및 제언}

최근 디지털 기술혁신과 함께 등장한 $\mathrm{QR}$ 코드 가상점 포는 고객이 원하는 다양한 장소에서 실시간으로 고객과 즉각적으로 대응할 수 있다는 점에서 효과적인 마케팅 수단으로 이용될 뿐 아니라 유통채널의 혁신을 가져오고 있다. 이러한 시점에서 본 연구에서는 질적 연구방법을 통해 소비자가 지각한 $\mathrm{QR}$ 코드 기반 가상패션점포의 혜 택과 위험요인을 탐색함으로써 소비자의 수용가능성을 진단하고, $\mathrm{QR}$ 코드 혁신기술을 활용한 패션 유통전략을 개발하는데 마케팅 시사점을 제공하고 있다.

전반적인 $\mathrm{QR}$ 코드 가상점포에 대한 인식을 살펴본 결과, 참여자들은 대중매체를 통해 " $\mathrm{QR}$ 코드 가상점포" 에 노출된 인지단계에 있으며, 기존의 모바일 커머스의 장점에 $\mathrm{QR}$ 코드가 갖는 증강현실과 위치기반 기술이 융 합되어 모바일 가상점포와는 차별적인 점포로 지각하고
있었다. 아직까지 $\mathrm{QR}$ 코드 가상점포를 수용하기에 최적 의 상황은 아니지만 이는 온라인과 오프라인의 장점을 결합한 멀티채널로서의 발전가능성을 시사하고 있으므로 (Lee \& Chung, 2011; Shim \& Go, 2012) 소비자 관점 에서 수용가능성은 낙관적이라 본다.

소비자가 지각한 $\mathrm{QR}$ 코드 스마트 가상점포의 혜택은 “감성적 소구”, “지각된 유용성”, “편재성”, “브랜드 홍 보"로 나타났다. 혜택 요인 중 지각된 유용성은 선행연 구에서 제시된 기술수용모델이 $\mathrm{QR}$ 코드 가상점포 맥락에 서 지지되고 있음을 확인하였다(Bae, 2010; Davis et al., 1989; Venkatesh et al., 2003). QR코드 기반 가상 점포에서는 고객접점의 물리적 위치에서 체험하는 감성 적 소구 뿐 아니라 증강현실과 위치기반서비스와 연동된 편재성은 이 기존의 인터넷 또는 모바일 가상점포와는 차별적인 혜택으로 지각되고 있어, 기존의 TAM구성요소 에 외재적 변인으로서 $\mathrm{QR}$ 코드 기술속성요소를 포함시켜 검증함으로써 확장된 기술수용모델을 추정해야 할 것이 다.

특히 패션제품의 경우, $\mathrm{QR}$ 코드 가상점포는 멀티채널 로서 효과적인 마케팅 프로그램을 개발하는데 장점으로 작용하고 있다. 예를 들면, 소비자의 감성을 자극하여 호 기심을 유발하고 사용욕구를 촉진시키는 "감성적 소구" 가 중요한 혜택요인으로 나타났다. 이는 소매 점포 맥락 에서 기술수용의 쾌락적 동기의 중요성을 제시한 선행연 구들을 지지하면서(Ko et al., 2009; Oh et al., 2009; Venkatesh et al., 2012) 효과적인 온오프라인 멀티채널 전략의 가능성을 시사하고 있다. 따라서 패션브랜드는 
$\mathrm{QR}$ 코드 가상점포 확대를 위해 물리적인 공간에 존재하 는 디스플레이 스크린을 감성적으로 디자인하여 소비자 의 호기심과 구매옥구를 자극해야 할 것이다. 또한, 마케 팅 관점에서 디스플레이 스크린과 $\mathrm{QR}$ 코드는 시각적으로 고유의 이미지를 소구할 수 있으므로(Choi, 2011a; Kim \& Kim, 2011) 브랜드 홍보에 의한 브랜드 정체성(brand identity)을 확립할 수 있을 뿐 아니라 $\mathrm{QR}$ 코드를 활용한 이벤트, 할인행사 등의 프로모션에 의한 가상점포의 체 험을 확대함으로써 마케팅 커뮤니케이션 효과를 높일 수 있을 것이다.

한편, QR코드 가상점포의 지각된 위험요인은 "사용의 복잡성”, “제품정보제한”, “기술 인프라 부족”, “지각된 비용"으로 분류되었다. 이러한 위험요인들은 선행연구에 서 제시한 기술수용모델의 예측변인과 비교할 때 충분히 기술성을 충족시키지 못하고 있어 $\mathrm{QR}$ 코드 기반 가상점 포가 대중화하는데 장벽이 되고 있음을 함축한다. 예를 들면, 사용의 복잡성 요인은 Davis et al.(1989)가 제시 한 “지각된 용이성”을 지지하지 못하고 있으며, "기술 인프라 부족"은 Venkatesh et al.(2003)이 제시한 기술수 용을 위한 촉진조건(facilitating condition)이 미흡한 상황 임을 내포하고 있다. 이러한 결과는 $\mathrm{QR}$ 코드를 이용한 가상점포에서 모바일 디바이스로 연결되는 경우, 스마트 폰을 이용한 제품 정보 확인시 화면을 확대/축소, 이동으 로 인한 신기술 사용의 번거로움에 기인한다고 본다. 무 엇보다도 $\mathrm{QR}$ 코드 활용의 장점은 즉각적인 인터넷 연결 로 제품이나 콘텐츠에 더 빨리 접근 가능할 수 있는 것 이나 (Lee et al., 2010), 현재 대부분 홈페이지에 연결 되어 회원가입 및 복잡한 결제단계를 거쳐야 하므로 소 비자들이 $\mathrm{QR}$ 코드 활용의 혜택을 제대로 경험하지 못하 고 있음을 제시하고 있다.

특히, 패션제품을 구매하는 과정에서 제품정보의 부족 과 비용에 대한 위험지각이 나타났는데 인터넷 쇼핑사이 트와 동일한 정보나 제품을 제시하는 경우 $\mathrm{QR}$ 코드를 스 캔하는 과정이나 가상점포의 방문이 번거롭게 느껴질 수 있으므로 스마트폰의 디바이스 특성에 맞는 가상점포만 의 전용상품과 컨텐츠를 개발하여 소비자가 필요로 하는 정보를 검색할 수 있는 개별화(Kwon \& Min, 2011)와 상호작용성(Shin \& Chang, 2013)을 동시에 갖춘 가상공 간의 쇼핑환경을 향상시켜 소비자들의 적극적인 참여를 유도해야 할 것이다.
본 연구는 FGI에 의한 질적 분석을 시도한 탐색적 연 구이기 때문에 본 연구의 결과를 모든 소비자에게 일반 화하는데 한계점을 갖는다. 따라서 향후연구에서는 양적

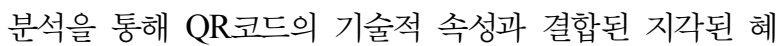
택과 위험요소의 타당하고 신뢰할만한 척도를 개발이 요 구되며, $\mathrm{QR}$ 코드기반 가상점포라는 점에서 기술수용모델 은 소비자가 구매의사결정과정에서 지각된 혜택과 비용 의 균형(trade-off)을 고려하여 추정해야 할 것이다. 아직 까지 $\mathrm{QR}$ 코드 가상점포의 성장 초기단계이므로 시간이 지남에 따라 $\mathrm{QR}$ 코드 가상점포수용의 결정변인의 차이를 규명하기 위한 횡단적 연구(longitudinal research)가 수 행되어 기술수용이론을 보완해야 할 것이다. 또한, 패션 마케팅 관점에서 $\mathrm{QR}$ 코드 가상 점포의 마케팅 믹스 요소 가 소비자의 고객접점 상황(자발적, 비자발적)에 따라 어 떻게 다르게 작용하는지 대안선택모델의 메카니즘을 밝 힘으로써 최적화된 "스마트" 가상점포 환경을 개발, 구축 할 필요가 있을 것이다.

주제어: 지각된 혜택, 위험, $\mathrm{QR}$ 코드, 가상패션점포, 질 적연구

\section{REFERENCE}

Baw, J. K. (2010). An empirical study on factors influencing the intention to acceptance of mobile application market, Journal of Korean Business Adminstration, 23(5), 2399-2422.

Carver, A.. \& Matus, R. (2012). QR codes in retail store, Nellymoser.com. Retrieved February 10, 2013, from http://www.nellymoser.com/action-codes /qr-codes-retail-stores

Choi, J. Y. (2011a). A study of the affects of design quick response code on consumer's attitude, Unpublished Master's thesis, Hongik University. Korea.

Choi, S. J. (2011b). Blowing virtual store in the distribution industry. Edaily.com. Retrieved February 1. 2013 from http://www.edaily.co.kr /news/NewsRead.edy ?SCD=DC14\&newsid= 
01092246596418168\&DCD=A00204\&OutLnkChk $=\mathrm{Y}$

Davis, F. D., Bagozzi, R, P., \& Warshaw, P. R. (1989). User acceptance of computer technology: A comparison of two theoretical models. Management Science. 35(8), 982-1003.

DeLone, W. H., \& McLean, E. R. (1992). Information system success:The quest for the dependent variable, Information System Research, 3(1), 60-95.

Grewal, D., Ailawadi, K. L., Gauri, D., Hall, K., Kopalle, P., \& Robertson, J. R. (2011). Innovations in retail pricing and promotions, Journal of Retailing, 87(1), 43-52.

Gu, A. (2011). The study on effect of store attributes on brand satisfaction and brand loyalty-Focusing on multi-channel retailing fashion brandsUnpublished Master's thesis, Yonsei University, Korea.

Han, D. H. (2012) Increasing virtual store. JungangIlbo, Retrieved February 1, 2013 from: http://article. joinsmsn.com/news/article/article.asp?total_id=7096 $924 \&$ cloc $=$ olink $\mid$ article $\mid$ default

Han, J. H. (2011). Gmarket, Opening 'virtual fashion store' in Myungdong station. Hankyung.com, Retrieved August 15, 2012, from: http:// kmomnews.hankyung. com/news/apps/news.sub _view?popup $=0 \&$ nid $=02 \& \mathrm{c} 1=02 \& \mathrm{c} 2=02 \& \mathrm{c} 3=00 \& \mathrm{n}$ key $=201110260958051$

Jang, W.(2011). A study on outdoor advertisements management system of ubiquitous using $Q R$ code. Unpublished Master's thesis, Hansei University, Korea.

Jung, G. \& Choi, W. (2010). Smart phone's location based service technology trend, TTA Journal 130, $75-81$.

Jung, H. Y. (2011). Booming virtual store, it is scared, shopping paradigm is changed. AsiaToday, Retrieved August 8, 2012 from: http://www. asiatoday.co.kr/news/view .asp?seq=568733

Jung, S. (2010). AR, Augmented Reality. Market Trends, Retrieved August 20, 2013 from: http://www. ssforum.org/upload_files/magazine/Vol37_MarketTr ends.pdf.

Kim, H. W., Chan, H. C., \& Gupta, S. (2007). Value-based adoption of mobile internet: An empirical investigation, Decision Support Systems, 43, 111-126.

Kim, M. G. (2011). Going to Homeplus' virtual store in the subway. ChosunBiz.com, Retrieved October 15, 2012 from: http://biz.chosun.com/site/data/html_ $\operatorname{dir} / 2011 / 08 / 25 / 2011082501628 . h t m l$

Kim, G. \& Jeon, H-J. (2011). A comparative investigation on technology acceptance model between professional groups and general consumers: Based on smart grid technology. Journal of Management \& Economics, 30(1), 53-80.

Kim, S. D. \& Lee, J. K.(2012). Efficient customer reception policy with QR code. Journal of IT Convergence Society for SMB, 2(1), 1-9.

Kim, T., Yun, H. \& Lee, C. C. (2012). Consumer segmentation based on usage motivation of 'QR-code Virtual Store': Application of Q-methodology. Entrue Journal of Information Technology, 11(2), 73-86.

Kim, Y. \& Kim, S. (2011). QR code utilizations for brand identity. Journal of Digital Design, 11(1), 377-387.

Kleijnen, M., de Ruyter, K. \& Wetzels, M(2007). An assessment of value creation in mobile service delivery and the moderating role of time consciousness, Journal of Retailing, 83(1), 33-46.

Ko, E., Kim, E. Y., \& Lee, E. K. (2009). Modeling consumer adoption of mobile shopping for fashion products in korea, Psychology \& Marketing, 26(7), 669-687.

Kwon, H. Y. \& Min, D. (2011). QRcode impact on attitude toward advertising, Korean Society of IT Services, 2011(5), 114-119.

Lee, J. W., Wang, X. M., Lee, J. H. \& Kim, B. S. (2010). A study on the marketing of exhibition hall with QR code of smart phone. Journal of KECRA, 11(4), 103-127.

Lee, K. Y. \& Chung, M. S. (2011). How QR codes are used in outdoor advertising, Journal of Outdoor 
Advertising Research, 8(2), 61-84.

Lee, K. Y. \& Kim, E. (2011). Characteristics of QR code Ad and Its effects on usage satisfaction and consumers' behavior as a commercial communication tool, The Korean Journal of Advertising, 22(3), 103-124.

Lee, S. H., Yang, S. K., Yoo, J. M. \& Lee, S. A. (2011). A study on the typology of the smart-phone advertisement through the technology convergence special reference to evolutionary model of $\mathrm{QR}$ code, Korean Business Review, 4(1), 51-72.

Moore, G. C. \& Benbasat, I. (1991). Development of an instrument to measure the perceptions of adopting an information technology innovation, Information Systems Research, 2(3), 192-222.

No sale person jeans store. (2012). Brand retail and design, Retrieved January 25, 2013 from: http://brandd.wordpress.com/2012/12/01/a-new-stor e-that-perfectly -combines-technology- withtra ditional-shopping/

Oh, S. H., Kim, Y. M., Lee, C. W., Shin, G. Y., Park, M. S. \& Jung, H. S. (2009). Consumer adoption of virtual stores in korea: Focusing on the role of trust and playfulness, Psychology \& Marketing, 26(7), 652-668.

Pin \& Fit, its first opening street mobile store. (2012). bntNEWS, Retrieved February 1, 2013 from: http://bntnews.hankyung.com/apps/news?popup $=0 \&$ $\mathrm{nid}=02 \& \mathrm{c} 1=02 \& \mathrm{c} 2=02 \& \mathrm{c} 3=00 \& \mathrm{nkey}=$ $201205290329333 \&$ mode $=$ sub_view

Shim, S. W. \& Go, A. (2012). The Study on Application of QR code to digital signage, The Korean Journal of Advertising, 23(5), 187-214.

Shin, D-H. \& Chang, W. S. (2013). QR code as interactive marketing communication media: Focused on technology acceptance model. Journal of the Korea Contents Association, 13(3), 76-86.
Shin, J. (2012). QR code, if utilized in the market, Marketing, 46(3), 71-75.

Song, A.N. (2012). Virtual store, Its possibility to progress as the 4th generation of distribution channel, Fashion Channel Retrieved August 30, 2013 from:http://www.fashionchannel.co.kr/ main09/news.php?table=papernews\&query=view\&u $\mathrm{id}=4839$

Thompson, R. L., Higginsm C. A. \& Howell, J. M. (1994). Influence of experience on personal computer utilization: Testing a conceptual model, Journal of Management Information Systems, 11(1), 167-187.

Top 10 QR Code Store examples(2013), shop2mobile, Retrieved February 2, 2013 from http://www. shop2mobi.com/virtual-qr-code-store-examples/

Venkatesh, V., Morris, M. Davis, G. B. \& Davis, F. D. (2003), User acceptance of information technology: Toward a unified view, Mis Quarterly, 27(3), 425-478

Venkatesh, V., Thong, J. Y. L. \& Xu, X. (2012). Consumer acceptance and use of information technology: Extending the unified theory of acceptance and use of technology, MIS Quarterly, 36(1), 157-178.

Whang, J. H. (2011). SK Telecom mobile commerce zone and Q store. MKNews, Retrieved Dec. 20, 2012 from:http://news.mk.co.kr/newsRead.php ?year $=2011 \&$ no $=389975$.

Yang, H-K. (2012). A study of Security weaknesses of QR codes and its countermeasures. JIWIT, 12(1), 83-89.

접 수 일: 2013. 09. 16 수정완료일: 2013. 10. 13 게재확정일: 2013. 10. 14 